\title{
Lean Alloys in PM: from the design to the sintering performance.
}

Authors: Raquel Oro ${ }^{(1)}$, Mónica Campos ${ }^{(2)}$, José Manuel Torralba ${ }^{(2)(3)}$, Carlos Capdevila ${ }^{(4)}$

(1)

Universidad Carlos III de Madrid, Av. Universidad 30, 28911 Leganés, Madrid, Spain, e-mail: roro@ing.uc3m.es, Telephone: +34 916249482 Fax: +34 91624 9430

(2) Universidad Carlos III de Madrid, Av. Universidad 30, 28911 Leganés, Madrid, Spain

(3) Institute IMDEA Materials, Avda. Del Mar Mediterráneo 20, 28918 Leganés, Spain

(4) Centro Nacional de Investigaciones Metalúrgicas (CENIM), Av. Gregorio del Amo 8, 28040 Madrid, Spain.

\begin{abstract}
Low alloy sintered steels with an optimized content of alloying elements require the use of promising candidates such as $\mathrm{Mn}$ and Si which can provide improved properties with minimum contents at a lower and less volatile price. The introduction of these alloying elements in the form of a master alloy powder prevents, to some extent, the oxidation and allows a proper "tailoring" of its composition to accomplish particular goals. In this sense, low melting point alloys are especially interesting since they provide the formation of a liquid phase which enhances sintering and promotes the homogeneous distribution of the alloying elements within the compact.

In this work, the "product developing" process of master alloys containing Fe-Mn-Si is described, from the theoretical design to the sintering performance. Low melting point compositions were calculated by using ThermoCalc ${ }^{\circledR}$ software and successively manufactured by gas atomization. Liquid phase features are described in terms of melting temperatures and wetting behavior. The effects of the liquid phase (produced by the added master alloys) are studied by differential thermal analysis and dilatometry. Besides, to depict the behavior of liquid phase during heating, interrupted sintering experiments under high cooling rates were carried out, and the results have been discussed through the microstructure examination.
\end{abstract}

Keywords: Lean Steels, Alloy Design, Low Melting Point Alloys, ThermoCalc, Liquid Phase Sintering, Wetting Angle. 


\section{Introduction}

In the powder metallurgy context, lean steels can be defined as low alloyed steels with a minimized content of alloying elements which maintain or even improve the level of properties in conventional sintered steels. Although the term "lean steels" has been recently coined, this particular goal has been pursued since the early seventies, when MCM and MVM master alloys were firstly introduced in the market ${ }^{1-5}$. At that time it was already known that the improvement of properties at a lower alloying cost should come by the introduction of elements such as $\mathrm{Cr}$, $\mathrm{Mn}$ or $\mathrm{Si}$, which had been used for many years in conventional wrought steels, but had limited applications in powder metallurgy due to their high affinity for oxygen. These researches posed the possibility of avoiding oxidation by the use of the "master alloy concept" since the introduction of elements with a high oxygen affinity in the form of a carbon containing master alloy could reduce its chemical activity and therefore protect them against oxidation. Besides, the melting of these master alloy particles during the sintering process proved to enhance sintering and promote the homogeneous distribution of the alloying elements.

During the last decades and fomented by the increasing interest in manganese sintered steels, successful master alloy systems containing manganese have reported impressive properties at a very low alloying cost $^{6-8}$. Besides manganese, silicon is also a very promising candidate which provides an excellent strengthening effect in sintered steels. Furthermore, by combining simultaneously $\mathrm{Mn}$ and $\mathrm{Si}$, sintered steels with excellent properties in the as sintered stage were obtained in the eighties by Klein et al. who reported small dimensional changes during sintering combined with a remarkably high strength $^{9-12}$. However, Mn-Si sintered steels have never reached the market.

In the attempt of re-opening the research on Fe-Mn-Si sintered steels, the master alloy route seems to be a promising option. It helps to prevent the oxidation, maintains the compressibility of the base powder and also allows a certain degree of flexibility in the composition when compared to prealloyed powders. However, in many cases, the problems are related with the difficulty of dissolving completely the master alloy particles, and distributing properly the alloying elements. In the last years, the development of software tools allows the design of master alloy compositions with a low melting point ${ }^{13,14}$. This ensures the formation of a liquid phase during the sintering process which facilitates the distribution of the alloying elements and also enhances sintering.

In this work, the system Fe-Mn-Si and Fe-Mn-Si-C have been assessed, in order to find low melting point compositions which ensure the formation of a liquid phase at the common sintering temperatures. However, the fact that the master alloy powders are present in a mix where diffusion processes take place long before the formation of the liquid phase raises some questions about the possible shifting in the melting temperature of the master alloy particles. The behavior of the liquid phase formed is clearly described here by the use of wetting experiments, DTA analyses, dilatometry and interrupted sintering experiments. 


\section{Materials and Experimental Procedure}

\section{a.Thermodynamic Calculations}

Thermodynamic calculations were performed with ThermoCalc software using the data base SSOL4. The lowest liquidus temperatures were calculated in the ternary system Fe-Mn-Si and in the quaternary system Fe-Mn-Si-C through the projections of the liquidus univariant lines. The liquidus lines of both phase diagrams were calculated over the whole range on compositions available in the database.

In order to calculate the liquidus univariant lines of these systems, a starting point is required for calculating and storing an initial equilibrium. The calculation of this initial equilibrium in an $n$-component system requires $n+2$ defined variables. The variables defined were pressure (1bar), size of the system (1mol), temperature, and $n-1$ compositions. The temperature and $n-1$ compositions were selected to be close to an invariant point of a lower order system, for instance, in the calculation of the quaternary system Fe-Mn-Si-C the ternary eutectic point found in the system Fe-Mn-Si was used. After defining this initial equilibrium, ThermoCalc can scan along up to five variables, such as for instance temperature and four composition axes. However, from these five variables at least three of them must be potentials; therefore no more than two chemical composition variables are allowed. This was solved by introducing two chemical compositions and substituting the chemical composition of the remaining elements by its chemical potential or activity ${ }^{14}$.

Master alloy compositions designed by ThermoCalc calculations were prepared as ingots for the wetting experiments and as gas atomized powder for thermal analyses.

\section{b.Wetting Experiments}

The materials used in the wetting experiments are summarized in Table 1 . The master alloy used as liquid phase promoter was prepared from high-purity Fe, Mn and Si by melting in an induction furnace under $\mathrm{He}$ atmosphere in order to obtain a dense specimen ( of approximately $2 \mathrm{~g}$ ) which can provide an homogeneous melting. For the wetting experiments, samples of approximately 30mg were cut from the ingot.

\begin{tabular}{|c|c|c|}
\cline { 2 - 3 } \multicolumn{1}{c|}{} & Material & Processing \\
\hline \multirow{2}{*}{ Substrates } & Sintered Iron & Pressing: $850 \mathrm{Mpa}$ \\
& ASC 100.29 & $\begin{array}{c}\text { Sintering: } 1250^{\circ} \mathrm{C}, 60 \text { min in } \mathrm{N}_{2-} \\
10 \mathrm{H}_{2}-0.1 \mathrm{CH}_{4}(\text { vol.\%) }\end{array}$ \\
\hline $\begin{array}{c}\text { Liquid-Phase } \\
\text { promoter }\end{array}$ & Master Alloy & $\begin{array}{c}\text { Melted in an induction furnace } \\
\text { under an He atmosphere }\end{array}$ \\
\hline
\end{tabular}

Table 1. Substrate and master alloys used for the wetting experiments.

Wetting experiments were carried out in an equipped furnace DSAHT designed by Kruss. The characteristics and configuration of this equipment are described elsewhere $^{15,16}$. Initially, the oxygen level in the furnace chamber was decreased using a vacuum system and keeping the pressure stable at $10^{-2}$ mbar. The experiments were run under Ar atmosphere at a normal pressure and a dew point of approximately $-19^{\circ} \mathrm{C}$ controlled in the 'gas outlet' exit. The pair drop-substrate was heated up to $800^{\circ} \mathrm{C}$ at a heating rate of $20^{\circ} / \mathrm{min}$. In the temperature range from $800^{\circ} \mathrm{C}$ to $1200^{\circ} \mathrm{C}$ the heating rate was decreased to $5 \% \mathrm{~min}$, and the wetting process was filmed at rate of $2 \mathrm{fps}$ ('frames per second'). 
The software "Drop Shape Analysis-DSA" was used for measuring the contact angle. Different measurement methods were chosen depending on the drop features. In the calculations, the time origin corresponds to complete melting of the droplet.

\section{c.Thermal Analyses}

The materials employed in thermal analyses are gathered in Table 2. Master alloy powders were obtained by gas atomizing in nitrogen in a lab scale atomizer from the company Atomising System LTD, (Sheffield, U.K).

\begin{tabular}{|c|c|c|}
\hline $\begin{array}{c}\text { Master Alloy } \\
\text { Powders }\end{array}$ & Fe-Mn-Si system & \multirow{2}{*}{ Gas atomized in $\mathrm{N}_{2}}$. \\
\cline { 2 - 3 } Base Powders & Water atomized plain iron powder & $\begin{array}{c}\text { Grade ASC 100.29 } \\
\text { (Höganäs AB) }\end{array}$ \\
\cline { 2 - 3 } & $\begin{array}{c}\text { Water atomized prealloyed powder } \\
\text { Fe-3Cr-0.5Mo (w.\%) }\end{array}$ & $\begin{array}{c}\text { Astaloy CrM } \\
\text { (Höganäs AB) }\end{array}$ \\
\hline Graphite & Natural graphite & $\begin{array}{c}\text { Grade UF4 } \\
\text { (Kropfmühl) }\end{array}$ \\
\hline
\end{tabular}

Table 2. Materials used in Thermal Analyses Studies.

Thermal analyses consist on differential thermal analyses (DTA) and dilatometry experiments. Table 3 shows the equipments used and the conditions applied for the different experiments.

\begin{tabular}{|c|c|c|}
\hline Experiment & Equipment & Conditions \\
\hline $\begin{array}{c}\text { Differential Thermal } \\
\text { Analysis (DTA) }\end{array}$ & $\begin{array}{c}\text { Setsys Evolution } 18 \\
\text { (Setaram Instrumentation) }\end{array}$ & $\begin{array}{c}\text { Atmosphere: } \mathrm{Ar} \\
\text { Heating rate: } 10 \% \mathrm{~min}\end{array}$ \\
\hline Dilatometry & $\begin{array}{c}\text { Netzsch STA 402C } \\
\text { pushrod dilatometer }\end{array}$ & $\begin{array}{c}\text { Atmosphere: } \mathrm{Ar} \\
\text { Heating rate: } 10 \% \mathrm{~min}\end{array}$ \\
\hline & $\begin{array}{c}\text { Atmosphere: } \mathrm{He} \\
\text { DT1000 Adamel Lhomargy } \\
\text { quenching dilatometer }\end{array}$ & $\begin{array}{c}\text { Heating rate: } 10 \% \mathrm{~min} \\
\text { Holding time: } 2 \mathrm{~min} \\
\text { Cooling rate: } \sim 75^{\circ} / \mathrm{min}\end{array}$ \\
\hline
\end{tabular}

Table 3. Thermal Analyses: equipments used and conditions applied.

Melting temperatures of the two master alloy powders were calculated by DTA analyses on loose powder with or without carbon additions. When present, carbon was added as graphite in an amount of 0.6w. \%.

Master alloy Fe-Mn-Si-C was selected for further thermal analyses. Melting of the master alloy particles during the sintering cycle of the steel was investigated by DTA experiments on green steel compacts containing base powder, master alloy powder and $0.6 \mathrm{w} . \%$ graphite, pressed at 600MPa. Two different base powders were used in these studies: plain iron and prealloyed iron powder. For each base powder, three scenarios are considered: no master alloy addition, 4w.\% master alloy and 20w.\% master alloy. This latter composition (20w.\% master alloy) was included with the aim of exaggerating the effects of the liquid phase formation.

Dilatometry experiments were carried out on green samples with plain iron base powder, $4 \% \mathrm{w}$. master alloy and $0.6 \% \mathrm{w}$. graphite pressed at 600MPa. The different blends were mixed for $30 \mathrm{~min}$ in a turbula mixer. 
The dimensional changes occurring due to the formation of the liquid phase were monitored through dilatometry experiments which allowed the identification of relevant temperatures in the sintering cycle. Afterwards, interrupted sintering experiments were carried out in a quenching dilatometer at the temperatures previously defined by the former dilatometry experiments. In step sintering runs the samples were hold for $2 \mathrm{~min}$ at the target temperatures and rapidly cooled in order to freeze any liquid phase formed. After the experiments, the samples were examined by optical microscopy.

\section{Results and discussion}

\section{a.Design of low melting point alloys.}

\section{$\mathrm{Fe}-\mathrm{Mn}$-Si System}

In the phase diagram of a $n$-component system, eutectic points are determined by the intersection of $n$ univariant lines where all $n$ lines lie above the intersection point ${ }^{13}$. The projections of the univariant lines in the phase diagram of the system Fe-Mn-Si were calculated with the software ThermoCalc and are represented in Fig. 1. An eutectic point is predicted from Fig. 1 at $1016^{\circ} \mathrm{C}$ with a composition Fe-38Mn-11Si (w.\%). A similar eutectic reaction is defined in the literature available at the same temperature and only at slightly different composition of Fe-30Mn-15Si (w.\%) (Table 4). The resemblance between both ThermoCalc data and the data provided by the literature indicates that an alloy with a composition close to the point predicted by ThermoCalc is likely to melt well below the common sintering temperatures $\left(1120-1250^{\circ} \mathrm{C}\right)$.
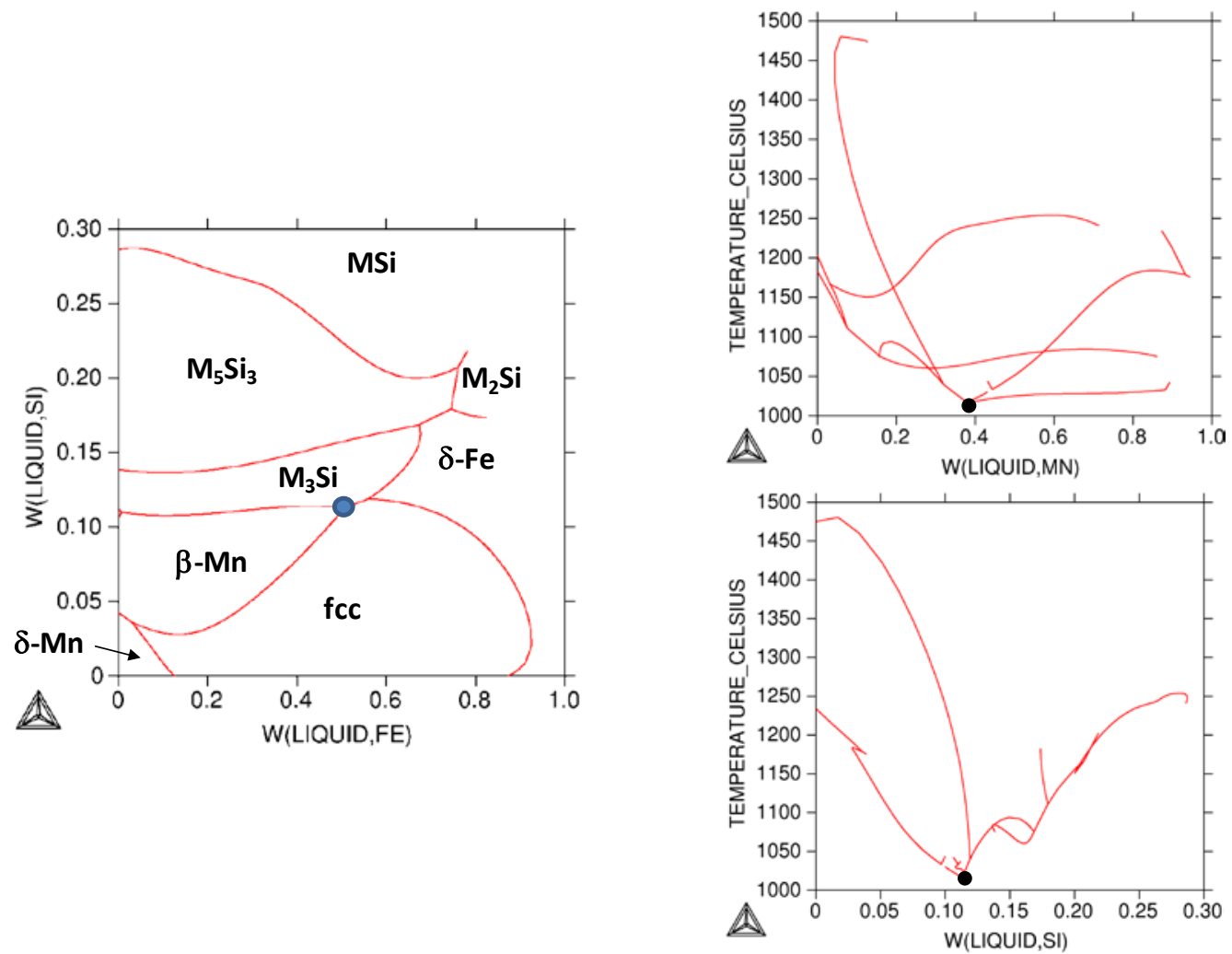

Fig. 1. System Fe-Mn-Si. Projection of the univariant lines of the liquidus surfaces onto the: Left: composition plane, Right: temperature vs. composition plane. 


\section{$\mathrm{Fe}-\mathrm{Mn}$-Si-C System}

The projections of the univariant lines in the system Fe-Mn-Si-C did not provide any intersection point of four univariant lines, therefore no eutectic points can be reported for this system (Fig. 2). Instead, two compositions which presented low liquidus temperatures (points $\mathrm{A}$ and $\mathrm{B}$ ) were considered interesting (Table 4). The liquidus temperatures in both points are similar, the main difference was found on the melting window (degrees between liquidus and solidus temperatures) which is less than $1^{\circ}$ for composition A and approximately $40^{\circ} \mathrm{C}$ for $\mathrm{B}$.

\begin{tabular}{|c|c|c|c|c|}
\hline \multicolumn{5}{|c|}{ Low Melting Point Compositions } \\
\hline System & Data & Composition & $\mathrm{T}$ & Reaction \\
\hline \multirow{3}{*}{ Fe-Mn-Si } & Calculated & Fe-38Mn-11Si & 1016 & $\begin{array}{c}\mathrm{L} \leftrightarrow \mathrm{M}_{3} \mathrm{Si}+\beta \mathrm{Mn}+\gamma \\
(\text { Eutectic) }\end{array}$ \\
\cline { 2 - 5 } & $\begin{array}{c}\text { Experimental } \\
\text { Ref. }{ }^{17}\end{array}$ & Fe-30Mn-15Si & $<1020$ & $\begin{array}{c}\mathrm{L} \leftrightarrow \mathrm{M}_{3} \mathrm{Si}+\gamma \\
(\text { Eutectic) }\end{array}$ \\
\hline Fe-Mn-Si-C & Calculated & $\begin{array}{c}\text { Fe-72Mn-10Si-1C } \\
(\mathrm{A})\end{array}$ & 988 & $\begin{array}{c}\mathrm{L} \leftrightarrow \beta \mathrm{Mn}+\mathrm{M}_{5} \mathrm{C}_{2}+\mathrm{M}_{3} \mathrm{Si} \\
\text { Incongruent Melting } \Delta T=0.8^{\circ}\end{array}$ \\
\cline { 2 - 5 } & $\begin{array}{c}\text { Fe-39Mn-11Si-0.3C } \\
(\mathrm{B})\end{array}$ & 998 & $\begin{array}{c}\mathrm{L} \leftrightarrow \beta \mathrm{Mn}+\gamma+\mathrm{M}_{3} \mathrm{Si} \\
\text { Incongruent Melting } \Delta T=39^{\circ}\end{array}$ \\
\cline { 2 - 5 } & Experimental & - & - & - \\
\hline
\end{tabular}

Table 4. Low melting point compositions in the systems Fe-Mn-Si and Fe-Mn-Si-C.
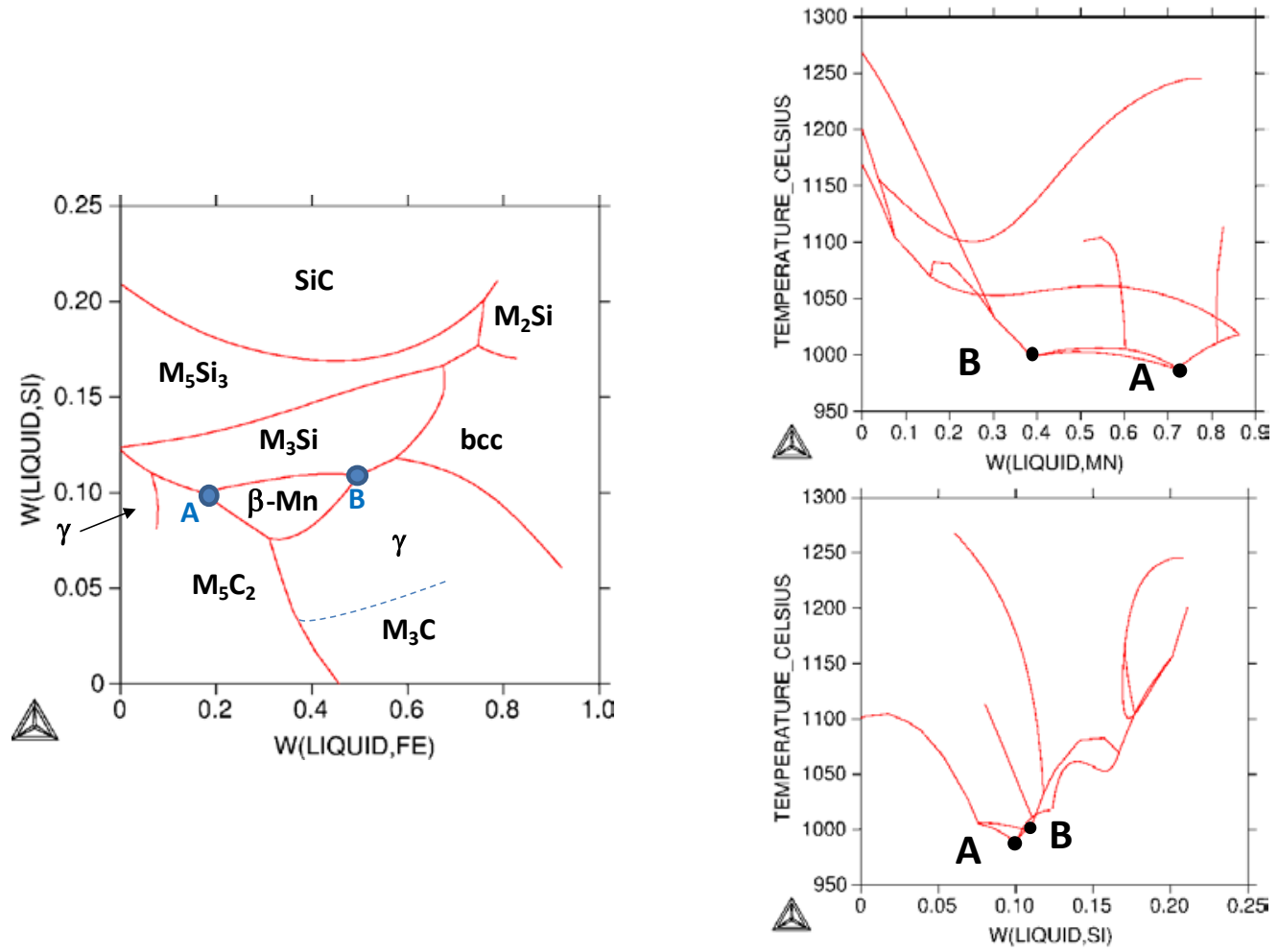

Fig. 2. System Fe-Mn-Si-C. Projection of the univariant lines on the liquidus surfaces onto the: Left: composition plane, Right: temperature vs. composition plane.

After these calculations, two compositions were selected for further studies: one system Fe-Mn-Si with a composition close to the calculated eutectic, and one system Fe-Mn-SiC with a composition similar to point B. Point B was selected for having a composition very similar to that of the system Fe-Mn-Si but including carbon. 


\section{b.Wetting Experiments.}

The wettability of the master alloy Fe-Mn-Si-C on plain iron substrates under $\mathrm{N}_{2}-10 \mathrm{H}_{2}$ atmosphere was reported in previous studies and compared with the wettability of $\mathrm{Cu}$ on the same type of substrates but under Ar atmosphere ${ }^{15,16}$. In those studies, the wetting angle provided by the master alloy was reported to be around $20^{\circ}$, while that of $\mathrm{Cu}$ was approximately $70^{\circ}$. Since the important differences between both wetting behaviors might be due to the different atmospheres used, wetting angle experiments have been carried out in this study using the same Fe-Mn-Si-C master alloy but under $\mathrm{Ar}$ atmosphere.

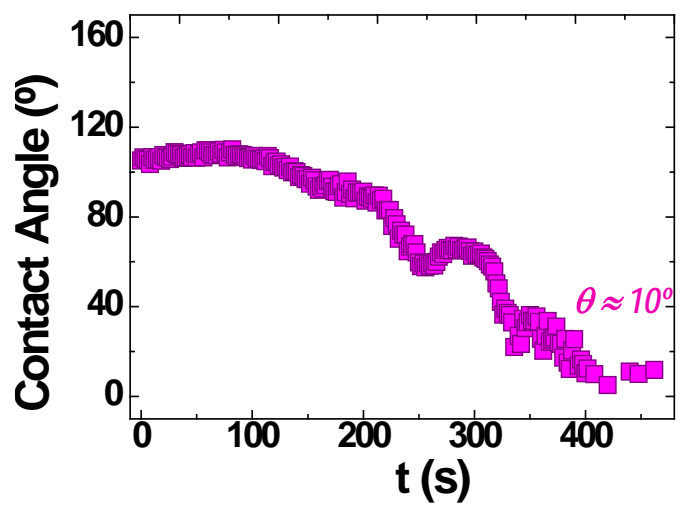

Fig. 3. Evolution of contact angle after drop formation under Ar atmosphere. Substrate: Plain Iron, Drop: Master alloy Fe-Mn-Si-C

An initial non wetting behavior is registered for the liquid master alloy on the iron substrate under Ar atmosphere (Fig. 3) and is due to the presence of an unreduced oxide layer on the surface of the iron substrate. With an Ar atmosphere and an iron substrate which does not contain any carbon, there are no reducing agents available for removing the oxides. This same effect has been observed in similar experiments where $\mathrm{Cu}$ was used as liquid promoter ${ }^{18}$.

A few minutes $(\approx 5 \mathrm{~min})$ after drop formation there is a decrease in the contact angle which evolves and reach very low values $\left(<10^{\circ}\right)$. This evolution of the wetting angle is due to the dissolution of the iron oxide layer by the liquid master alloy. The ability of this master alloy to dissolve the iron substrate is due to the chemical compatibility between the iron substrate and the liquid formed ${ }^{16}$.

The conditions used for the wetting experiments performed represent the worst case scenario where no reducing agents are available. The fact that the master alloy can wet the iron substrate even under such unfavorable conditions reveals one of the benefits of using a master alloy with a dissolutive behavior.

\section{c.Liquid phase formation during sintering.}

During the sintering cycle and due to the promoted diffusion of elements at high temperatures there might be a change in the master alloy composition that affects its melting behavior. In this sense, the most important influence is that of carbon, which presents the highest diffusion rate in iron.

The melting of the master alloy powders with and without graphite was studied through DTA experiments (Fig. 4). According to the DTA curves, the liquid phase is formed at around $1135^{\circ} \mathrm{C}$ in the Fe-Mn-Si master alloy, while in the system with carbon (Fe-Mn$\mathrm{Si}-\mathrm{C}$ ) is around $1072^{\circ} \mathrm{C}$. When graphite is added the melting behavior in the Fe-Mn-Si alloy is considerably different, while that of Fe-Mn-Si-C alloy remains almost 
unchanged. In this latter case, the presence of carbon on the initial composition of the master alloy hinders the diffusion of this element in the master alloy particle and there are no changes on its melting temperatures. In case of the Fe-Mn-Si system, the diffusion of carbon leads to the formation of a liquid phase at lower temperatures. Moreover, the temperatures of liquid phase formation are found to be similar to those obtained with the Fe-Mn-Si-C master alloy. These results indicate that, for the Fe-MnSi system studied, the addition of small amounts of carbon $(<1 \mathrm{w} . \%)$ either in the initial master alloy composition or by addition of graphite, results beneficial since it helps to reduce the melting point and therefore ensures the formation of a liquid phase at the sintering temperature.
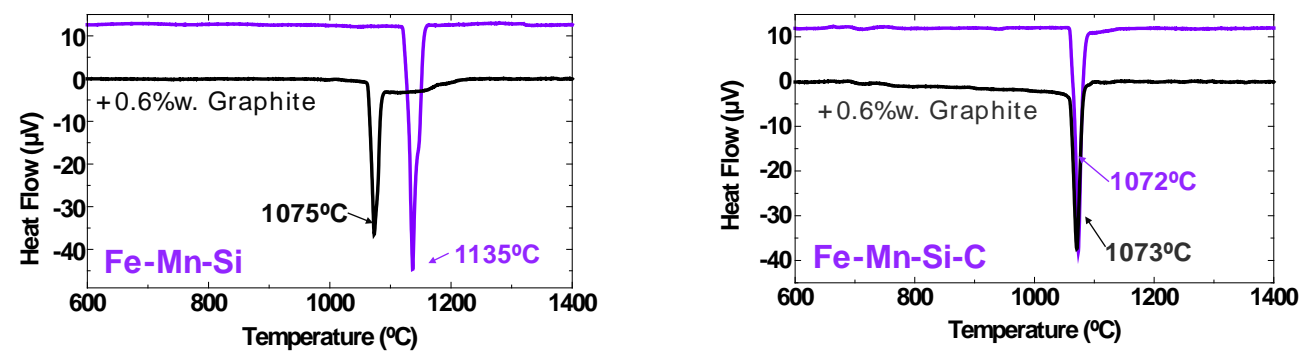

Fig. 4. DTA experiments for two different master alloy atomized powders (Left: Fe-Mn-Si, Right: Fe-Mn-Si-C) with and without additions of graphite.

The Fe-Mn-Si-C master alloy was selected for thermal studies on green steel compacts since the presence of carbon in the master alloy composition might help to prevent the oxidation during the heating stage. Fig. 5 shows the DTA curve of steels containing either plain iron (left) or prealloyed iron (right) as base power, and increasing amounts of master alloy.

The results are similar for both base powders, which indicate that the chemical composition of the base powder is not affecting the melting behavior of the master alloy. If no master alloy is added only the $\alpha \rightarrow \gamma$ transition is observed in this range of temperatures. Adding 4\%w. of master alloy an additional endothermic peak is found at the melting temperature of the master alloy. When the amount of master alloy is increased to 20\%w., two endothermic peaks are observed. The first endothermic transformation occurs at the melting temperature of the master alloy, and the second one at approximately $15-20^{\circ}$ above. The emergence of this second endothermic transformation is linked to the presence of a higher amount of liquid in the mix, and is very likely associated with the dissolution of the base powder which is emphasized when the amount of dissolving liquid increases.
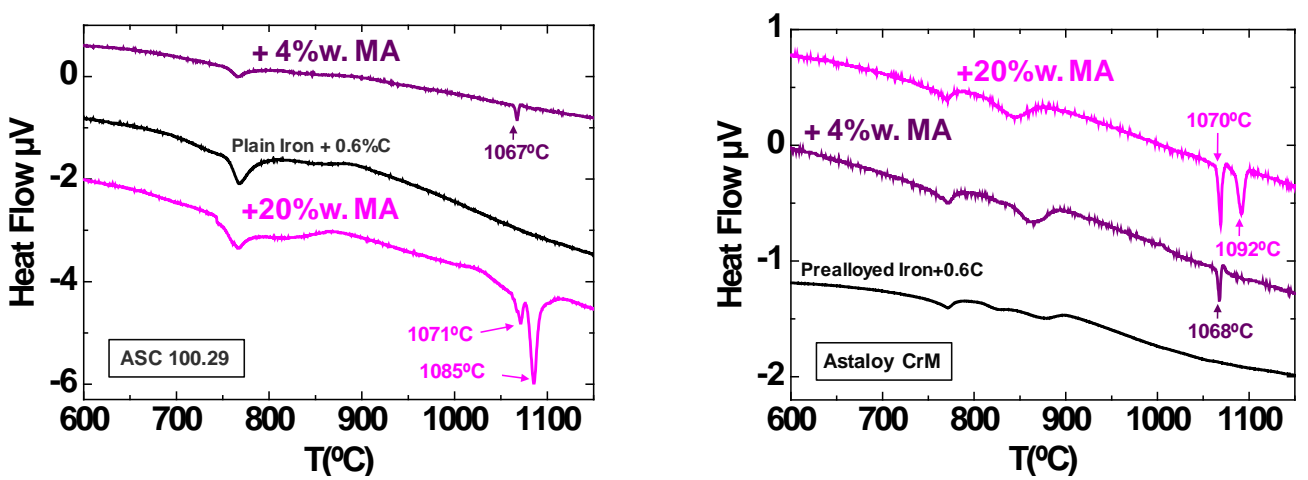

Fig. 5. DTA experiments performed with two different base powders (Left: Plain Iron, Right: Cr prealloyed iron) adding increasing amounts of master alloy. 
The formation of a liquid phase usually has an influence on the dimensional changes that the sample undergoes during the sintering cycle. The dilatometry curve obtained for green compacts containing 4\%w master alloy and plain iron as a base powder, sintered under $\mathrm{Ar}$ atmosphere is presented in Fig. 6. An abrupt change in the slope of the dilatometry curve is taking place during the heating cycle and is associated with the liquid phase formation. This change in the slope is clearly seen with the derivative of the dilatometry curve and is registered at temperatures between $1110-1175^{\circ} \mathrm{C}$.

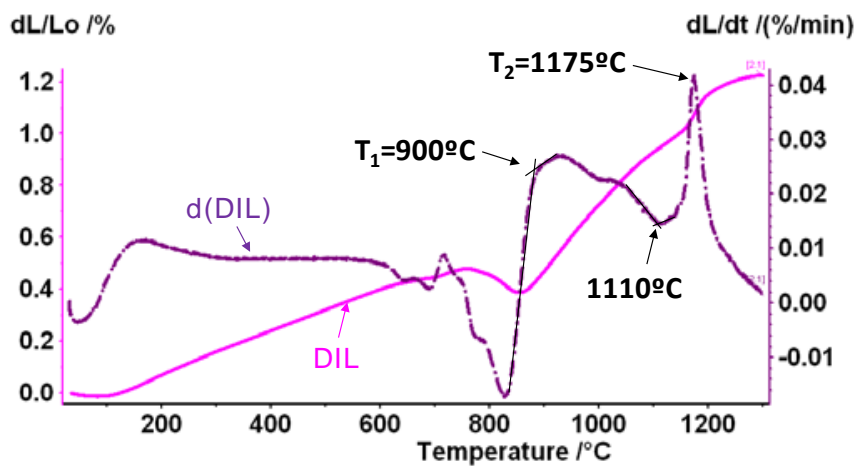

Fig. 6. Dilatometry curve and derivative.

In order to understand the phenomena taking place during the liquid phase formation, step sintering experiments were carried out by heating at defined temperatures and cooling rapidly in order to freeze any liquid phase formed. The temperatures were selected based on the dilatometry curve in Fig. 6 and are defined in Table 5.

\begin{tabular}{|c|c|c|}
\hline Step & Temperature & Description \\
\hline 1 & $\mathrm{~T}_{1}$ & After $\alpha \rightarrow \gamma$ transition \\
\hline 2 & $\mathrm{~T}_{2}+10^{\circ}$ & $10^{\circ}$ over the evidence of liquid formation \\
\hline 3 & $\mathrm{~T}_{2}+50^{\circ}$ & $50^{\circ}$ over the evidence of liquid formation \\
\hline 4 & 1250 & Typical high sintering temperature \\
\hline
\end{tabular}

Table 5. Sintered stages used for the step sintering experiments.

The dilatometry curves obtained after the step sintering experiments are represented in Fig. 7. From these curves it is evident that the sample in step 1 was cooled just after $\alpha \rightarrow \gamma$ transformation, and in steps 2 and 3 close after the change in the slope. 


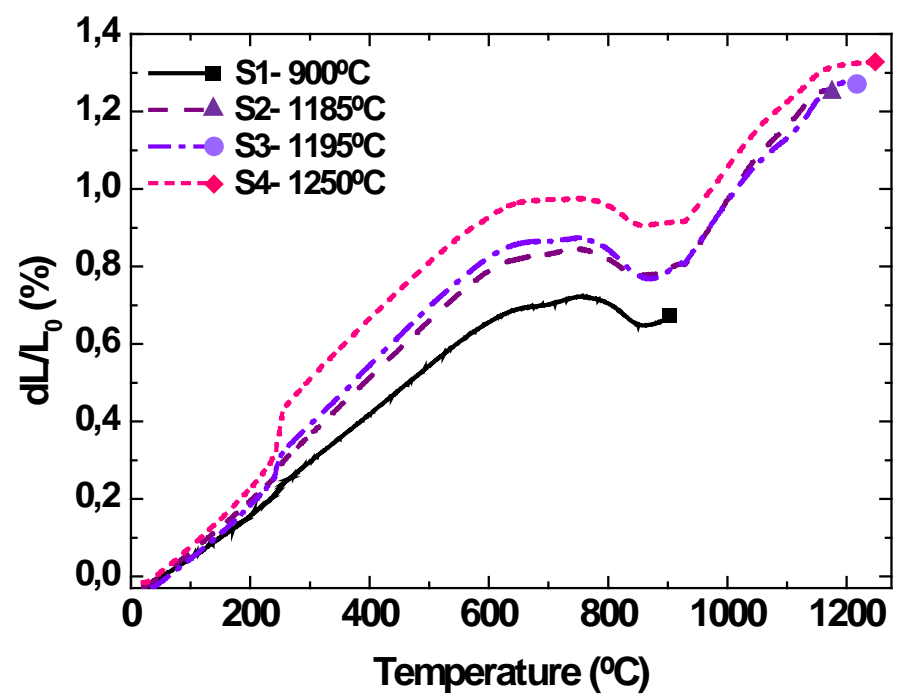

Fig. 7.Dilatometry curves for four Step Sintering experiments

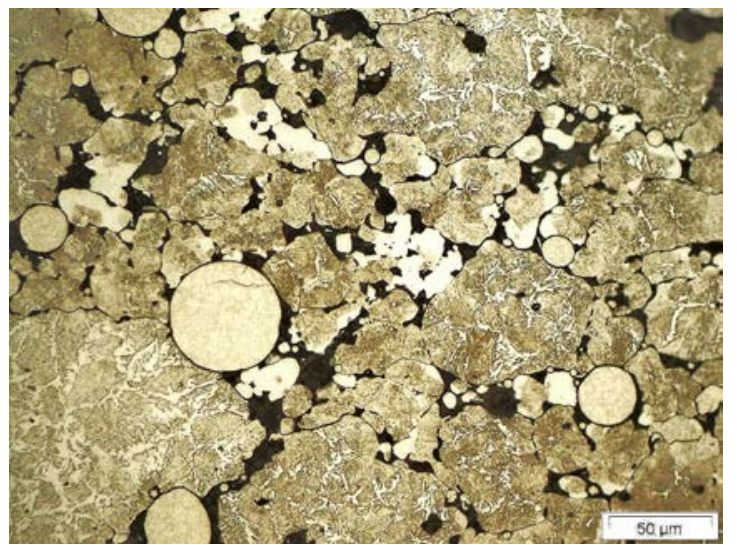

Stage 1

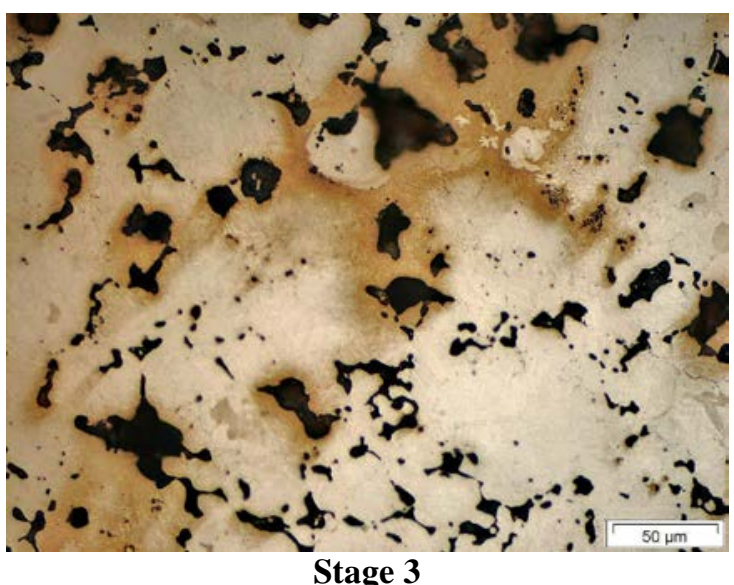

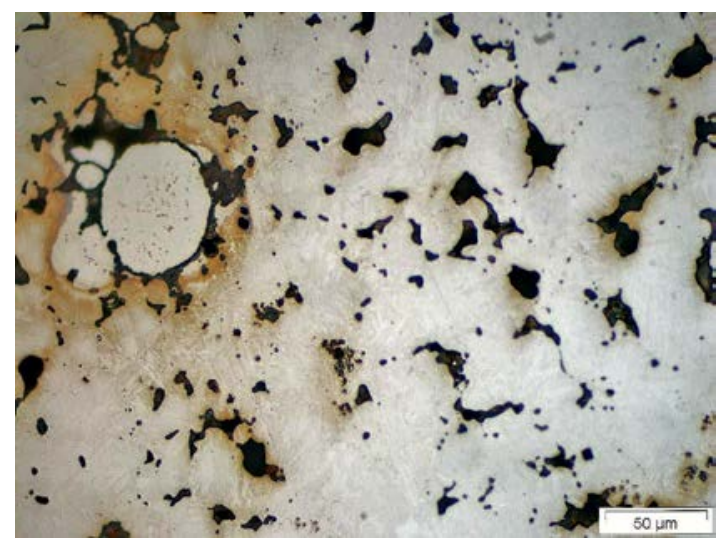

Stage 2

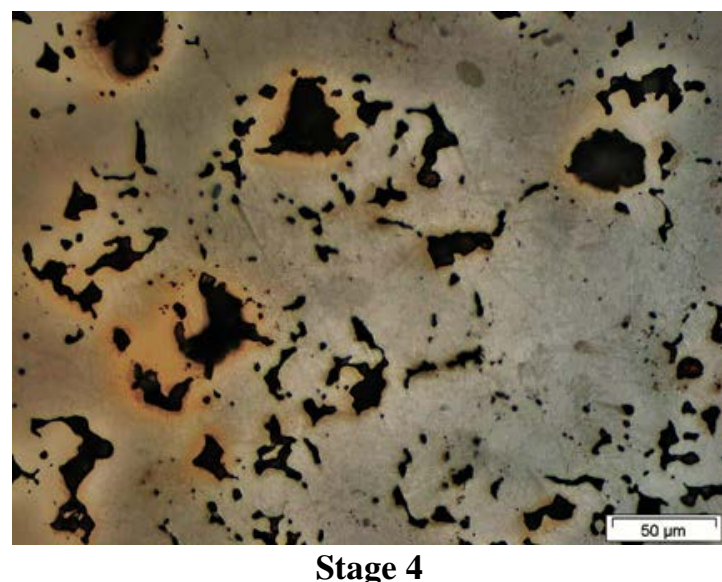

Fig. 8. Micrograph of the samples after Step Sintering etched with Nital 2\%.

The micrographs of the samples obtained after step sintering experiments are show in Fig. 8. Image of Step1 evidences that carbon, which was introduced as graphite, is completely distributed within the mix long before melting of the master alloy. Stages 2 and 3 show the evolution of the melting process. It is clearly seen how even before the end of the melting process, the liquid available has already started to dissolve the surface of the iron base powder. An increase in the sintering temperature is helping to complete the melting of the master alloy particles and is always accompanied by 
dissolution of the surrounding base powder. At high sintering temperatures, the master alloy particles melted completely and high alloyed areas are noticeable around the secondary porosity left. The interrupted sintering experiments confirm the efficiency of the liquid phase formed in promoting the introduction of the alloying elements in the base powder particles, which is somehow helped by the dissolution phenomena.

\section{Conclusions}

- Master alloy compositions which ensure the formation of a liquid phase at temperatures lower than the common sintering temperatures have been found for the systems Fe-Mn-Si and Fe-Mn-Si-C by the use of thermodynamic calculations performed with the software ThermoCalc.

- The melting point of the master alloy seems to be influenced by the diffusion of carbon in the master alloy particles, but only when there is no carbon already present in the master alloy composition. For the compositions studied here, diffusion of carbon seems to be beneficial for lowering the melting temperature of the alloying particles.

- The fact that the master alloys studied can dissolve part of the iron base particles has been shown to be beneficial for wetting. This could be especially interesting when the oxide layer in the surface of the iron particles is not completely reduced, since the master alloy might be able to dissolve partly the oxide barrier, improving the wetting.

-The dissolutive behavior of these master alloys combined with an iron base powder has been proved both by DTA experiments and by interrupted sintering experiments, and is thought to be advantageous in order to improve the dissolution of the alloying elements in the iron base particles.

Acknowledgements The authors wish to thank C. Gierl and H. Danninger from the Technical University of Vienna Austria for their assistance in dilatometry analyses. The financial support provided by Höganäs AB Sweden, by the MICINN Spain through the project ENE2009-13766-C04-03 and by the CAM Spain through the project S2009/MAT-1585, is gratefully acknowledged.

\section{References}

1. G. Zapf and K. Dalal: 'Introduction of High Oxygen Affinity Elements Manganese, Chromium and Vanadium in the Powder Metallurgy of P/M Parts', Modern developments in powder metallurgy, 1977, 129-152.

2. G. Hoffmann and K. Dalal: 'Development and present situation of low alloyed PM steels using MCM and MVM master alloys', Powder Metallurgy International|Powder Metallurgy International, 1979, 177-180.

3. G. Schlieper and F. Thummler: 'High strength heat-treatable sintered steels containing manganese, chromium, vanadium and molybdenum', Powder Metallurgy International|Powder Metallurgy International, 1979, 172, 174-176.

4. S. Banerjee, G. Schlieper, F. Thümmler, and G. Zapf: 'New Results in the Master Alloy Concept for High Strength Sintered Steels ', Progress in Powder Metallurgy, 1980, 13, 143157. 
5. S. Banerjee, V. Gemenetzis, and F. Thummler: 'Liquid-Phase Formation During Sintering of Low-Alloy Steels with Carbide-Base Master Alloy Additions', Powder Metallurgy, 1980, 23(3), 126-129.

6. P. Beiss: 'Alloy Cost Optimization of High Strength Mn-Cr-Mo Steels with KeroseneAtomized Master Alloy ', Advances in Powder Metallurgy \& Particulate Material,, 2006, 1(7), 12-20.

7. F. Castro, M. Sarasola, S. Sainz, and T. Gomez-Acebo: 'Processing routes for obtaining novel high performance Mn-containing PM steels', in 'Progress in Powder Metallurgy, Pts 1 and 2', (eds. D. Y. Yoon, et al.), 705-708; 2007.

8. S. Sainz, V. Martinez, M. Dougan, F. Baumgaertner, and F. Castro: 'Sinterability, Hardenabilility and Mechanical Properties of Mn-Containing PM Steels through the Use of a Specially Designed Fe-Mn-C Master Alloy', Advances in Powder Metallurgy \& Particulate Materials, 2006, 95-108.

9. A. N. Klein, R. Oberacker, and F. Thummler: 'High-Strength Si-Mn-Alloyed Sintered Steels - Microstructure and Mechanical-Properties', Powder Metallurgy International, 1985, 17(1), 13-16.

10. A. N. Klein, R. Oberacker, and F. Thummler: 'High-Strength Si-Mn-Alloyed Sintered Steels - Sinterability and Homogenization', Powder Metallurgy International, 1985, 17(2), 71-74.

11. A. N. Klein, R. Oberacker, and F. Thummler: 'Development of new high strength Si-MnAlloyed sintered steels.', Modern Developments in Powder Metallurgy, 1985, 16, 141-152.

12. F. Thummler, A. Klein, and R. Oberacker: 'Method for powder metallurgical production of structural parts of great strength and hardness fron Si-Mn or Si-Mn-C alloyed steels', Patent, 1990.

13. H. Du and J. E. Morral: 'Prediction of the lowest melting point eutectic in the Fe-Cr-MoV-C system', Journal of Alloys and Compounds, 1997, 247, 122-127.

14. T. Gomez-Acebo, M. Sarasola, and F. Castro: 'Systematic search of low melting point alloys in the Fe-Cr-Mn-Mo-C system', Calphad-Computer Coupling of Phase Diagrams and Thermochemistry, 2003, 27(3), 325-334.

15. R. Oro, M. Campos, A. R. Garcia-Cebadera, and J. Torralba: 'Liquid Phase Sintering Optimization in PM Steels by Studying the Wetting Behavior at High Temperature of Master Alloys on Iron Substrates.', Proceedings EuroPM2010, Florence, 2010, EPMA.

16. R. Oro, M. Campos, and J. Torralba: 'Study of high temperature wetting and infiltration for optimising liquid phase sintering in low alloy steels', To be published in "Powder Metallurgy" ( DOI 10.1179/1743290111Y.0000000007 ), 2011.

17. M. S. I. T. MSIT ${ }^{\circledR}$ and N. Lebrun: 'Iron - Manganese - Silicon', in 'Thermodynamic Properties - Ternary Alloy Systems: Phase Diagrams, Crystallographic and Thermodynamic Data • Iron Systems, Part 4', 2008, Springer-Verlag.

18. R. Oro, E. Bernardo, M. Campos, and J. Torralba: 'Liquid phase sintering: spreading, wetting and infiltration behavior in a successful reference system, Fe-C-Cu', EuroPM2011, Barcelona (Spain), 2011, EPMA. 